\title{
Modern family: Texas critical care clinicians need to know about informal marriage
}

\author{
Jamie M. Crist JD, MA
}

\begin{abstract}
Critical care clinicians are legally and ethically obligated to identify the appropriate surrogate decision-makers for patients who lack capacity and cannot make medical decisions for themselves. When the identification of the appropriate surrogate is streamlined, patient care is improved due to an uninterrupted and consistent plan of care that adheres to patient preferences. However, the process of identifying this "appropriate" person can be complex, especially as interpersonal relationships have evolved over time. One such modern family relationship is informal marriage, a Texas-specific relationship formerly known as "common-law" marriage. Though crucially important, this relationship can be difficult to recognize and is frequently misunderstood.

Utilizing a case study, this paper seeks to show how an informal marriage can impact medical decision-making by outlining what makes a relationship an informal marriage and provides tools to assist clinicians with identifying it. In an age in which non-traditional relationships are more common, Texas critical care clinicians should be familiar with informal marriage and recognize it in their patients to efficiently identify surrogates and therefore improve patient care.
\end{abstract}

Keywords: informal marriage, common-law marriage, Texas, medical ethics, advance care planning, critical care

\section{INTRODUCTION}

The family unit is in flux now more than ever. An increasing number of Americans are choosing cohabitation as an alternative to marriage,${ }^{1}$ and those who do marry are waiting longer to do so. ${ }^{2}$ Social norms are progressing and changing, and public policy is evolving in response. These complex interpersonal relationships can make it difficult for clinicians to identify a patient's next-of-kin or surrogate for medical decision-making - which is necessary if a patient lacks capacity, a common scenario in intensive care units (ICUs). In Texas, this identification process can be further complicated due to a unique relationship

Corresponding author: Jamie Crist

Contact Information: Jamie.m.crist@gmail.com

DOI: $10.12746 /$ swrccc.v8i34.623 known as informal marriage. Once called "commonlaw" marriage, this relationship, though present in Texas for more than a century, is still misunderstood. Modern forms of family increase the challenges.

Fortunately, informal marriage is relatively easy to recognize once the elements of the relationship are understood. This paper seeks to address some misconceptions surrounding informal marriage and to provide guidance for clinicians to identify this relationship. Furthermore, this paper emphasizes the need for clinicians to recommend that patients in non-traditional relationships execute advance directives, particularly medical powers of attorney, to streamline identification of surrogates and better adhere to patient preferences.

\section{Case Presentation}

Mr. Jones is a 35-year-old man who presents to the hospital with altered mental status and left-sided 
weakness. After imaging, he is found to have a basilar artery thrombus for which he undergoes a mechanical thrombectomy and reperfusion. Etiology of the occlusion is suspected to be cocaine use. After several days in the ICU, his neurological status is poor. $\mathrm{He}$ intermittently follows commands by wiggling his toes, but he does not open his eyes. His right pupil is fixed, his left pupil is sluggish, and his cough reflex is absent. Gag and corneal reflex are present.

Mr. Jones's family consists of his significant other, Emma, and his father, David. The patient and Emma have been in a relationship for 20 years and refer to each other as life partners. They have two young children and live in the same home together, but they use different last names. Emma says they "never got around" to getting married. His father speaks to his son often but lives across the country. He flies in for a family meeting with the physicians to discuss goals of care.

The physicians inform the family that due to the damage his brain sustained, Mr. Jones most likely will be ventilator dependent, unable to swallow, and not capable of much interaction for the remainder of his life. The decision of whether to proceed with a tracheostomy and permanent feeding tube placement or transition to comfort care is posed to the family. After hearing his poor prognosis, Emma states that she does not think the patient would want to live in a state in which he cannot take care of himself or interact with his children. She feels comfort care is most appropriate. David, however, states his son is a fighter who has beaten other serious ailments in the past. He believes that his son will surprise the doctors if he is given the chance to improve. He asks to move forward with aggressive measures.

Without documents naming Emma as Mr. Jones's agent for health care decisions, the physicians are legally bound to follow David's interpretation of his son's wishes. The patient receives a tracheostomy and permanent feeding tube and is transferred to a long-term care facility.

\section{Discussion}

Most people in modern times get married formally by following statutorily outlined steps. In early
America, however, completing this traditional method became more difficult. People were spreading out over the continent, meaning civil servants able to perform marriages were often unavailable and carrying identification paperwork was uncommon. ${ }^{3}$ A substitute to the formal, statutory method was needed to preserve institution of marriage. Judges-ruling on divorces, estate settlements, and legitimacy claimssaw the potential for great injustice if they were to determine that no marriage existed in cases of long-standing, significant relationships due to a mere lack of following the statutory steps. ${ }^{4}$ With the freedom to decide based on what would be fairest, judges would rule that a marriage existed based on the facts of the case-such as living together, raising a family together, and otherwise acting married-even if the couple did not formally marry. Over time, as judges recognized the same factors repeatedly as those that created a non-formal marriage, the "common-law" of marriage was created. To be "common-law married," or to meet the judge-made requirements, became the substitute method of marriage to bridge the gap when formal marriage was not feasible.

Since the circumstances which necessitated common-law marriage are less common today, most states have abolished the practice. In Texas, however, common-law marriage still exists in some form. In 1969, the Texas legislature took the requirements of common-law marriage that judges had developed and codified them into statute, changing the name in the process to informal marriage, or "marriage without formalities." Technically, common-law marriage no longer exists in Texas, though the concept of forming a marriage without state involvement has been preserved through informal marriage. Colloquially, however, the terms common-law and informal marriage are used interchangeably.

The issue of informal marriage in a medical setting is most often raised when someone mentions that the patient's significant other is not "actually" or "really" married to the patient, or when there is uncertainty as to the seriousness of the relationship. In such circumstances, familiarity with the concept of informal marriage can help to eliminate confusion and streamline future plan of care discussions with both the patient 
and family. As illustrated by this case, the presence or absence of an informal marriage has a significant impact on patient care.

There are three requirements that must be met for a couple to be informally married in Texas. A relationship becomes an informal marriage when a couple (1) agrees that they are married, then (2) lives together in Texas as spouses, while (3) representing to others that they are married. ${ }^{5}$ All three elements must be present simultaneously, and the individuals must have the capacity to marry. This means that they must be at least 18 years old, unrelated, and not married to someone else. The legal status created by informal marriage is identical to that created by a formal marriage, including inheritance rights, spousal privilege, and parental rights. Both same-sex and different-sex couples can be informally married. Informally married couples typically must get formally divorced. ${ }^{6}$

The essential difference between formal and informal marriage is the method by which the couple expresses their consent to be married to each other. ${ }^{4}$ In a formal marriage, the couple's consent is expressed through the ceremony, with an officiant and witnesses. In an informal marriage, the consent is expressed via cohabitation as spouses. Informally married couples must live together and be known in the community as married, while a formally married couple could choose to keep their marriage a secret and live separately, while still maintaining the legal status of a marriage.

There are two common misconceptions about informal marriage in Texas. The first is that there is a duration requirement, or a length of time a couple must live together before being considered married. Texas does not have a duration requirement, though other states do. The second misconception involves the "agreement" element. Many people interpret this element to mean that the couple has agreed to be married at some point in the future, ${ }^{7}$ i.e., engaged. But this is incorrect. ${ }^{8}$ Instead, the couple must have agreed to be married at some point in the past and then carried on as spouses.

Although clinicians cannot make legal judgments on the validity of patient marriages, it is within the purview of a medical professional to ascertain who the surrogate decision-maker is for an incapacitated patient. As such, familiarity with the evidence commonly used to prove an informal marriage can be helpful. The "agreement" element can be the most difficult to identify. In cases similar to this one, only one-half of the couple can speak to the nature of their relationship. Signifiers of a past agreement to be married are the terms the couple uses for each other. If they refer to their partner as "fiancée" or "boyfriend," the couple is almost certainly not informally married. Instead, consistent use of terms like "husband," "spouse," and sometimes "life partner" more clearly signify the couple's past intent to be married to each other and thus current status as informally married. Asking the capacitated partner to describe when and how they and the patient decided to marry is another useful strategy to identify this element. ${ }^{9}$

The other elements are easier to spot. Living together in Texas "as spouses"10 requires a showing that the couple share an address and treat each other as spouses in day-to-day life. This includes factors such as raising children together, having joint savings or checking accounts, filing joint tax returns, and purchasing property together. The third and final element turns on whether the couple has a reputation in the community of being married, ${ }^{11}$ or whether the relationship is "public knowledge." Evidence that the couple "holds themselves out" as married includes use of the same last name and consistent references to each other as spouses. It can also include corroboration from other family members or individuals who know the couple outside the hospital, like a member of the clergy. In combination, the second and third elements provide circumstantial evidence that the couple did in fact agree to be married, though it is not an automatic inference. ${ }^{12}$

Informal marriage need not have the reputation of being complex or troublesome. For critical-care clinicians, knowing the history, elements, and misconceptions regarding this relationship can lead to better patient care. Patients in modern relationships who regain the capacity to make their own medical decisions should be encouraged to fill out a medical power of attorney promptly to avoid any future disagreements as to the appropriate surrogate. In instances in which there are conflicting opinions from family or 
friends on whether the couple is informally married, and for decisions regarding withholding or withdrawing life-sustaining therapy from patients for whom the appropriate surrogate is uncertain, consulting a clinical ethicist or a member of the risk management/legal team of the hospital is the best approach. ${ }^{13}$

\section{DISCLAIMER}

The information provided in this paper does not, and is not intended to, constitute legal advice; instead, this information is for general informational purposes only. Readers of this paper should contact an attorney to obtain advice with respect to any particular legal matter.

\section{ACKNoWledgment}

The author would like to acknowledge Mary Anderlik Majumder, J.D., Ph.D, and thank her for her support while writing this paper.

Article citation: Crist JM. Modern family: Texas critical care clinicians need to know about informal marriage. The Southwest Respiratory and Critical Care Chronicles 2020;8(34):73-76

From: Baylor College of Medicine, Center for Medical Ethics and Health Policy, Houston, TX; Houston

Methodist Hospital; Biomedical Ethics Consult Service, Houston, TX

Submitted: $2 / 23 / 2020$

Accepted: 4/7/2020

Reviewer: Steven Urban MD

Conflicts of interest: none

This work is licensed under a Creative Commons

Attribution-ShareAlike 4.0 International License.

\section{REFERENCES}

1. Pew Research Center, November 2019, "Marriage and Cohabitation in the U.S."
2. Wendy Wang and Kim Parker, 2014. "Record Share of Americans Have Never Married: As Values Economics and Gender Patterns Change." Washington, D.C.: Pew Research Center's Social \& Demographic Trends project, September.

3. Clarice M. David, Common-Law Marriage in Texas, $21 \mathrm{Sw}$ L.J. 647 (1967).

4. Grigsby v. Reib, 105 Tex. 597, 608 (1913).

5. Tex. Fam. Code. Ann. § 2.401(a) (2005).

6. But see, Tex. Fam. Code. Ann. § 2.401(b) (a rebuttable presumption that the couple did not agree to be married is created if no proceeding in which a marriage must be proved is filed within 2 years of the parties' separation).

7. Aguilar v. State, 715 S.W.2d 645 (Tex. Crim. App 1986) (“A present intention to be married in the future is not enough. The parties must intend to be husband and wife from the moment of the agreement onward.")

8. However, an intent to be ceremonially married in the future does not automatically negate the existence of a present informal marriage. See, e.g., Small v. McMaster, 352 S.W.3d 280 (Tex. App. 2011) (couple planned to be "properly" married later in a church).

9. Crenshaw v. Kennedy Wire Rope \& Sling Co., 327 S.W.3d 216 (Tex. App. 2010) ("The unchallenged testimony of one of the parties to the marriage constitutes direct evidence the parties agreed to be married and amounts to more than a scintilla.")

10. Court cases are almost exclusively regarding heterosexual relationships, therefore the language stated in court cases and the statute reads, "as husband and wife." However, since Obergefell v. Hodges, 576 U.S._, 135 S. Ct. 2584 (2015), all marital rights cases are retroactive. Therefore, "spouses" is more inclusive.

11. Small v. McMaster, 352 S.W.3d 280 (2011) (determining whether the couple had a 'reputation in the community' for being married.)

12. Crenshaw v. Kennedy Wire Rope \& Sling Co., 327 S.W.3d 216 (Tex. App. 2010) ("The conduct of the parties as well as proof of cohabitation and representations to other may constitute circumstantial evidence of an agreement to be married depending upon the facts of the case.")

13. For routine medical treatment decisions, the law does provide a safe haven from legal or civil liability for physicians or hospitals acting in good faith under the Act and does not constitute a failure to exercise due care in the provision of the medical treatment. Consent to Medical Treatment Act. Tex. Health \& Safety Code Ann. § 313.007(b). 